\title{
An exploratory study of patient portal adoption and use in multiple clinical specialty departments
}

\author{
Stephen E. Bronsburg, Nova Southeastern University, USA, bronsbur@nova.edu \\ Marcia Durity, Nova Southeastern University, USA, duritym@mynsu.nova.edu \\ Michelle M. Ramim, Nova Southeastern University, USA, ramim@nova.edu
}

\begin{abstract}
A patient portal is an effective vehicle for health information dissemination, a key component of knowledge management. The focus of this exploratory research study was to examine how demographic variables of gender and age as well as clinical specialty grouping affect patient portal adoption and use at a hospital in South Florida. We conducted a semi-structured interview focusing on portal adoption and usage with 768 patients at their scheduled appointments. Results showed that younger participants aged 20 to 30 used the portal significantly less than other age groups in the study. Patients between the ages of 41 and 60 use the portal the most. Findings suggest a need to expand patient portal functionality, portal education and awareness to increase patient portal use. These preliminary findings will support a broader effort investigating patient portal use and barriers such as eHealth literacy skills.
\end{abstract}

Keywords: Informatics, Patient Portal, Knowledge Management, eHealth, Electronic Health Records Adoption and Use.

\section{Introduction}

\section{Background}

The Health Information Technology for Economic and Clinical Health Act, 2009 (HITECH), moved the health information technology needle further by initiating electronic health (eHealth), namely electronic health records (EHRs) and patient portals. The resources came through the rules of Meaningful Use (MU) administered by the Centers for Medicaid and Medicare (Aljabril et al., 2018; Centers for Medicare and Medicaid Services, 2013). Patient portals were now mainstream. The initial enrollment into a patient portal signifies adoption, while engagement is actively using the portal (Aljabri et al., 2018). To reduce any confusion, we replaced the word "engage" to "use" in this study. Secure information access and effective information dissemination are core components of the knowledge management (KM) processes (Croasswait \& Curtice, 1994). Knowledge sharing through social networks, such as patient portals, is a human strategy in KM (Choi \& Lee, 2002). Choi and Lee (2012) explained that the human strategy in KM is learning from experienced and skilled people. The seamless transfer of healthcare information between provider and patient through a portal has shown to empower patients. Patient portals give secure access to the patient's personal health information (PHI). This data and information are measurable and verifiable, and when used in the proper setting 
becomes knowledge, which in turn becomes of great importance in the healthcare decisionmaking process. Patients can now actively participate in the decision-making process with their healthcare team by actively using the patient portal. Patients are increasingly assuming more responsibility for their healthcare; they are demanding increased value from their healthcare organization's KM processes (Cepeda-Carrion, Martelo-Landroguez, Leal-Rodriguez, \& LealMillan, 2016). The knowledge sharing process coupled with patient demand and increased patient use of portals has forced hospitals to focus on improving their quality of medical record documentation (Pavani, 2008; Gowen et al., 2009). eHealth is the use of information and communication technologies for health (World Health Organization, 2018) and allows for a culture of knowledge sharing, ultimately increasing collaboration between patient and healthcare providers. There is a lack of KM and patient portal research creating a need to explore this unique relationship, in terms of impact on patient outcomes (Razzaque \& Karolak, 2010). Patient portals link the right people, in the right context using the right technology format. Patient portals are eHealth systems and they "create opportunities to improve knowledge, self-efficacy, and engagement" (Ancker et al., 2015, p. 254).

Prior to 1996, the issues of a fragmented United States healthcare system coupled with multiple administration concerns including hand-written medical records and storage systems made medical record retrieval problematic (Furukawa et al., 2014; Rittenhouse et al., 2017). The Health Insurance and Portability and Accountability Act (HIPAA) of 1996 for the first time made it possible for patients to access their protected PHI and medical records (United States Department of Health and Human Services, 2018). PHI had become more accessible, which has put a strain on confidentiality and security. As access avenues multiplied, patients became more concerned about privacy and security. Patients are deeply concerned over who has access to their personal health record, and what level of access (Dhillon, et al., 2018). Dhillon (2018) further stated that there is a discrepancy between what patients expect in the confidentiality of their medical record and actual. Patients want control over their information (Cain \& Hanania, 2013; Schwartz et al., 2015).

There are multiple stages of Meaningful Use. Meaningful Use - Stage 1 criteria stipulate capturing health data and sharing it. Stage 2 focuses on health information exchange and patientcontrolled data, namely patient portals (Centers for Medicare and Medicaid Services, 2013). The Office of the National Coordinator for Health Information Technology (NCO), "What is a patient portal?" (2019), considered a patient portal to be a crucial component of eHealth and defined patient portals as, "secure online website that gives patients convenient, 24-hour access to personal health information from anywhere with an Internet connection using a secure username and password, patients can view personal health information" (ONC Patient Portal Benefits, 2019). Patient portals allow access to PHI including current and past medical history and test results. Portals open communication between patients and providers, allowing patients to request medication refills, and manage their appointments. Through a proxy, one can manage a loved one's health information in the portals to improve overall patient care, "Nearly one-in-five individuals care for or make health care decisions for someone with a medical or behavioral condition or disability" (ONC Data Brief, 2018, p. 9). Patient portals are accessible through a variety of devices including computers, laptops, or mobile devices such as tablets or smartphones. Notable challenges or barriers with utilization of patient portals are the 
cumbersome registration process, health literacy, patient education, computer access and difficulty using the portal (Baldwin, Singh, Sittig, \& Giardina, 2017; Mayberry, Kripalani, Rothman, \& Osborn, 2011; NCO Patient Portal Benefits, 2019; Osborn, Mayberry, Wallstonka, Johnson, \& Elast, 2013; Zickmund et al., 2008).

MyChart is the patient portal used at the hospital at the time of this exploratory. MyChart is a product of Epic, used with their electronic medical record software (Epic, 2019). MyChart is a free online portal allowing patients secure access to PHI and communication with their healthcare team. Some of the information a patient can access include test results, physician progress notes, preventive care information, and upcoming appointments as well as to set appointments, review current health issues, email the healthcare team all from multiple communication devices with a secure Internet service. The range of information accessed and the ability to download information varies by the portal. The hospitals portal in this study offers eVisits or telemedicine with stipulations. Loved ones may, with permission, access the portal. According to Sarkar Karter, Liu, Adler, Nguyen, and Lopez (2011) and Tenforde, Nowacki, Jain, and Hickner (2012), patients most frequently visit their patient portal to check laboratory results, check medication refills, communicate with their provider via email and to make appointments. The portal is in English, Spanish, and there is an interpreting company available for other languages. The portal is HIPAA compliant and falls under the hospital's security protocols. Once an account is set up through their healthcare provider, users will connect to the Internet, enter the account code, and create a username and password. Patient portals provide increased effectiveness in healthcare by the transfer of personal health information from the healthcare organization to the patient, allowing active engagement in the decision-making process. This improves clinical outcomes, increases provider-patient communications, quality of care, improves patient self-management, reduces costs, and increased patient satisfaction (Hoogenbosch et al., 2018; Kruse, Argueta, Lopez, \& Nair, 2015; Osborn, Maryberry, Mulvaney, \& Hess, 2010; Tenforde et al., 2011). Limited use or engagement of patient portals by both patient and provider may hinder meaningful clinical outcomes leading to nominal patient improvements (Miller, Latulipe, Melius, Qunadt, \& Arcury, 2016; Sun et al., 2018).

The purpose of this study was to examine how demographic variables of gender and age as well as clinical specialty groupings impact on patient portal adoption and use. The hospital's use rate for the patient portal at the time of this study was 47\%. According to the ONC Data Brief (2018), $48 \%$ of patients are not offered information on how to access online medical records via a patient portal. Of the $52 \%$ that are, only $28 \%$ used the patient portal at least once in the past year, and $26 \%$ of those used it three to six times in the past year (ONC Data Brief, 2018).

\section{Methodology}

\section{Design, Setting, and Participants}

The data collection part of this exploratory study occurred over a three-month period in 2017. Participants in this study were existing patients of a South Florida hospital. Patients who were at their scheduled appointment were approached by research team members, and asked if they wanted to participate in a brief focused semi-structured interview. This was strictly voluntary, and no PHI were collected. Interviews were paper based, conducted in English, and recorded by 
the research team members. The interview took approximately five minutes to complete. The focused semi-structured interviews were conducted face-to-face in four locations within the hospital and two separate off-site clinics that were part of the hospital system for a total of six separate locations. Each location consisted of multiple healthcare clinical service specialties. We focused our efforts on these locations because of their heavy patient traffic volume. The first location and the off-site clinic (sixth location) both included internal medicine, but at two separate physical locations. The second location and the off-site clinic (fourth location) both included speech therapy, two separate physical locations. All six locations had a designated patient check-in desk. At the patient check-in, hospital staff confirmed appointments as well as which provider the patient was seeing for that visit that day, and then asked patients if they signed up for the portal. Through our unstructured observation, it was obvious that asking patients about the portal did not happen consistently. The first location included Internal Medicine, Infectious Disease, Endocrinology, and Endocrine Surgery. The second location included Dermatology, Speech Therapy, and Otolaryngology. The third location included Orthopedic Surgery, Hand Surgery, Pain Management, Podiatry, Rheumatology, Nephrology, and Pulmonary Medicine. The fourth location, an off-site outpatient clinic of the hospital, included Physical, Occupational, and Speech Therapy. The fifth location included Hematology and Oncology, and the sixth location, an off-site outpatient clinic of the hospital included Physical Therapy, Cardiac Rehabilitation, Pulmonary Rehabilitation, Geriatric, and Internal Medicine.

\section{Measures}

\section{Data Collection}

The main purpose of the focused semi-structured interview was to determine patient portal adoption and use. The focused semi-structured interview included questions that allowed the participants express their opinions on the patient portal as well as their usage. Prospective participants who voluntarily agreed to participate in the interview were first asked to self-declare their gender, age range, area of specialty medicine they were there to see that day and which provider. Participants were asked the following questions: How long they were a patient of the hospital. If they were signed up for the portal and accessed it? If so, how long? If not, are they interested in signing up? We asked the participants at their check-in if they signed up for the portal. The last two questions were two semi-open queries. Are there any barriers they have encountered when accessing the portal? Do they have any comments regarding the portal? After the semi-structured interview, we compiled the aggregate data. No PHI data such as patient name, medical record number, home residency addresses, phone number, or any other identifying information were collected.

During the one-on-one semi-structured interview process, we acknowledge that many patients were interested in obtaining more information about the patient portal. We were able to assist many of the patients who were interested in signing-up for the portal. We provided these participants with an overview of the patient portal and gave them brochures (English or Spanish as well as a language translation service contact if needed) detailing more information. Those that were not signed-up but expressed an interest also received a brochure, as well as an 
explanation of the portal and the sign-up process. For those interested in signing up for the patient portal, we guided them through the sign-up process, which was as follows: Once the patients received an activation code from the front desk staff, we worked with the patient one-onone to complete the online registration form using a borrowed hospital laptop. This entailed patients entering into the portal system sensitive patient information as well as patient identifiable information including creating a personalized user name and password.

While conducting the focused semi-structured interviews, we had several opportunities to observe the front desk staff's workflow with each of the departments regarding the patient signin process. Our only interest in front desk workflow was to see if staff approached patients regarding the patient portal, and if so, what was the enrollment process for those not signed up. Patients that were not signed up but expressed interested triggered the front desk staff to first, $\log$ into the system and generate a code necessary for the patient to enroll. Next, they gave minimal instructions and the educational pamphlet on the portal. As stated previously, asking about the portal was not consistent across departments and process seemed more sporadic than routine. This was not a priority of the front desk. There was a kiosk in the hospital on the first floor next to internal medicine with a designated computer and MyChart sign. However, most times it was offline, the sign was not inviting, and the pamphlets at the kiosk ran out the first few days we were there observing. It seemed like the hospital staff did not replenish it.

\section{Results}

\section{Findings and Data Analysis}

Table 1 displays the characteristics of gender and age group of patient portal users and nonusers. The only conditions to be included in the study were, patients had to be at least 20 years old, have an appointment in one of the six hospital locations and voluntarily give consent. We felt that this would capture the general population of those seeking services at the hospital. We interviewed 768 participants for this exploratory research study, of which $43.8 \%$ (337 of 768) were male and $56.1 \%$ (431 of 768) were females. Higher rates of patient portal use are associated with younger, female and those that are well educated (Ancker et al., 2015; Haun, Patel, Lind, \& Antinori, 2015; Irizarry, DeVito, \& Curran, 2015). Of all participants usage of the patient portal for males was 25.0\% (192 of 768), and for females was 32.9\% (253 of 768). Overall all males who participated had a portal usage of $56.9 \%$ (192 of 337), while all females who participated had patient portal usage of $58.7 \%$ (253 of 431). Overall all male participants who were nonusers of the patient portal were $43.0 \%$ (145 of 337), and of all female participants who were nonusers that number was $41.2 \%$ (178 of 431).

Age group was broken out into seven categories. We felt it was necessary to look at several groups to be able to tease out generational patient portal utilization (Aljabril et al. 2018; Oest, Hightower, \& Krasowski, 2018). Age categories were as follows: 20-30 (28), 31-40 (104), 41-50 (193), 51-60 (211), 61-70 (153), 71-80 (31), and 80+ (48). Participant portal usage by age group shows that the majority $57.5 \%$ (256 of 445$)$ of those who use the portal were between the ages of 41 to 60 , year olds ( 41 to $50 \& 51$ to 60 age groupings). Of all participants in the study, $57.9 \%$ (445 of 768) stated they are using the patient portal. This is $10.9 \%$ above what the hospital reported. 
Table 1. Characteristics of Portal Users and Nonusers - Gender and Age ( $\mathrm{N}=768)$

\begin{tabular}{|c|c|c|c|c|c|}
\hline \multirow[t]{2}{*}{ Characteristics } & \multicolumn{2}{|c|}{ User $(n=445)$} & \multicolumn{2}{|c|}{ Nonuser $(n=323)$} & \multirow{2}{*}{$\begin{array}{c}\text { Total }(\mathrm{N}=768 \\
\text { No. }\end{array}$} \\
\hline & No. & $\%$ & No. & $\%$ & \\
\hline Gender & & & & & \\
\hline Male & 192 & $43.2 \%$ & 145 & $44.8 \%$ & 337 \\
\hline Female & 253 & $56.8 \%$ & 178 & $55.2 \%$ & 431 \\
\hline $\begin{array}{l}\text { Total } \\
\text { Age Group }\end{array}$ & 445 & $100 \%$ & 323 & $100 \%$ & 768 \\
\hline $20-30$ & 4 & $00.9 \%$ & 24 & $07.4 \%$ & 28 \\
\hline $31-40$ & 58 & $13.0 \%$ & 46 & $14.2 \%$ & 104 \\
\hline $41-50$ & 117 & $26.2 \%$ & 76 & $23.5 \%$ & 193 \\
\hline $51-60$ & 139 & $31.2 \%$ & 72 & $22.2 \%$ & 211 \\
\hline $61-70$ & 86 & $19.3 \%$ & 67 & $21.0 \%$ & 153 \\
\hline $71-80$ & 18 & $04.2 \%$ & 13 & $04.0 \%$ & 31 \\
\hline $80+$ & 23 & $05.2 \%$ & 25 & $07.7 \%$ & 48 \\
\hline Total & 445 & $100 \%$ & 323 & $100 \%$ & 768 \\
\hline
\end{tabular}

Table 2 displays medical specialty department grouping location of patients that are using the portal and those that are not. Location 3 had the highest percentage of users $32.1 \%$, followed by Location 1 with 19.8\%, and Location 2 at 17.5\%. Overall 58\% (445 of 768) of the respondents used the portal.

Table 2. Characteristics of Portal Users and Nonuser - Hospital Department Areas (N=768)

\begin{tabular}{|c|c|c|c|c|c|c|c|c|}
\hline \multirow[t]{2}{*}{ Department } & \multicolumn{2}{|c|}{$\begin{array}{l}\text { Engaged } \\
(n=445)\end{array}$} & \multicolumn{2}{|c|}{$\begin{array}{c}\text { Not } \\
\text { Engaged } \\
(\mathrm{n}=\mathbf{3 2 3})\end{array}$} & \multirow{2}{*}{$\begin{array}{c}\begin{array}{c}\text { Total } \\
(\mathrm{n}=\mathbf{7 6 8})\end{array} \\
\text { No. }\end{array}$} & \multicolumn{3}{|c|}{$\begin{array}{c}\text { Asked to Sign-in } \\
\text { at the } \\
\text { Front Desk }\end{array}$} \\
\hline & No. & $\%$ & No. & $\%$ & & No & Yes & Total \\
\hline $\begin{array}{l}\text { Location 1: Internal Medicine, } \\
\text { Infectious Disease, and } \\
\text { Endocrinology and Endocrine } \\
\text { Surgery }\end{array}$ & 88 & $19.8 \%$ & 57 & $17.6 \%$ & 145 & 76 & 69 & 145 \\
\hline $\begin{array}{l}\text { Location 2: Dermatology, Speech } \\
\text { Therapy, and Otolaryngology }\end{array}$ & 78 & $17.5 \%$ & 57 & $17.6 \%$ & 135 & 62 & 73 & 135 \\
\hline $\begin{array}{l}\text { Location 3: Orthopedic Surgery, } \\
\text { Hand Surgery, Pain Management, } \\
\text { Podiatry, Rheumatology, Nephrology, } \\
\text { and Pulmonary Medicine }\end{array}$ & 143 & $32.1 \%$ & 115 & $35.7 \%$ & 258 & 177 & 81 & 258 \\
\hline $\begin{array}{l}\text { *Location 4: Physical, Occupational, } \\
\text { and Speech Therapy }\end{array}$ & 21 & $4.7 \%$ & 14 & $4.3 \%$ & 35 & 23 & 12 & 35 \\
\hline $\begin{array}{l}\text { Location 5: Hematology and } \\
\text { Oncology }\end{array}$ & 64 & $14.4 \%$ & 40 & $12.4 \%$ & 104 & 62 & 42 & 104 \\
\hline $\begin{array}{l}\text { *Location 6: Physical Therapy, } \\
\text { Cardiac Rehabilitation, Pulmonary } \\
\text { Rehabilitation, Geriatric and Internal } \\
\text { Medicine }\end{array}$ & 51 & $11.5 \%$ & 40 & $12.4 \%$ & 91 & 67 & 24 & 91 \\
\hline Total & 445 & $100 \%$ & 323 & $100 \%$ & 768 & 467 & 301 & 768 \\
\hline
\end{tabular}

Table 3 captures data on participant portal usage over time listed in years. Patient portal usage in the 1 to the 3 -year range was $41.5 \%$ (185 of 445). Patient portal use for the 4 to 5 year range was 
$14.1 \%$ (63 of 445). That number nearly doubles to $27.1 \%$ (121 of 445$)$ for those using the portal for the 6 plus year range. Those using the patient portal for less than 1 year were $17.1 \%$ (76 of 445).

Using a chi-square $\left(\chi^{2}\right)$ test of independence, we found that the 20-31-year-old age group used the patient portal significantly less $(14 \%)$ than all the other ages $\chi^{2}(6, \mathrm{~N}=768)=30.28, \mathrm{p}<0.001$. This is consistent with similar finding (Wallace et al., 2016). No difference was found between males and females $(p=0.738)$ or department $(p=0.867)$ in terms of portal usage.

Table 4 displays the breakout on how participants found out about the patient portal. The front desk carried the bulk of the responsibility with approximately $39.2 \%$ (301 of 768) of the participants stating that the front desk approached them regarding the patient portal. Followed by the physician and nurse at 20.0\% (154 of 768), and the practicum students at 18\% (137 of 768). The front desk, physician and nurse accounted for nearly two thirds or 59.2\% (455 of 768).

Table 3. Patient Portal Usage by Department by Years $(\mathrm{N}=445)$

\begin{tabular}{|c|c|c|c|c|c|}
\hline \multirow[t]{2}{*}{ Department/Provider } & \multicolumn{5}{|c|}{ Number of Years Using the Patient Portal } \\
\hline & $<1$ Year & 1-3 Years & 4-5 Years & $6+$ Years & Total \\
\hline $\begin{array}{l}\text { Location 1: Internal Medicine, Infectious disease, } \\
\text { Endocrinology, Endocrine Surgery }\end{array}$ & 11 & 40 & 12 & 25 & 88 \\
\hline $\begin{array}{l}\text { Location 2: Dermatology/Speech Therapy, } \\
\text { Otolaryngology }\end{array}$ & 15 & 37 & 4 & 22 & 78 \\
\hline $\begin{array}{l}\text { Location 3: Orthopedic Surgery, Hand Surgery, } \\
\text { Pain Management, Podiatry, Rheumatology, } \\
\text { Nephrology \& Pulmonary Medicine }\end{array}$ & 21 & 59 & 27 & 36 & 143 \\
\hline $\begin{array}{l}\text { *Location 4: Physical, Occupational and Speech } \\
\text { Therapy }\end{array}$ & 2 & 7 & 2 & 10 & 21 \\
\hline Location 5: Hematology/Oncology & 15 & 29 & 9 & 11 & 64 \\
\hline $\begin{array}{l}\text { *Location 6: Physical Therapy, Cardiac } \\
\text { Rehabilitation, Pulmonary Rehabilitation, Geriatric } \\
\text { and Internal Medicine }\end{array}$ & 12 & 13 & 9 & 17 & 51 \\
\hline Total & 76 & 185 & 63 & 121 & 445 \\
\hline
\end{tabular}

* Off-site clinics

The results of adoption and use of the patient portal allowed us to place participants into one of four groupings. The first group included patients who knew about the portal and were active users. In the second group were patients who knew about the portal and signed up but were not users of the portal. In the third group were patients who knew about the portal yet had not signed up, and in the fourth group were patients who did not know about the portal. We discovered that most of the participants were in either in the first or the third group. The focused semi-structured interview had two questions, which gave participants an opportunity to express themselves. The first question: Are there any barriers for you to accessing the patient portal? The second question: Do you have any comments regarding the patient portal? Participants in the third group listed the following barriers or reasons for non-portal engagement: limited technical ability and 
computer literacy skills; time-consuming; primary care services received in other healthcare organization; inadequate access to computers and the Internet; and reluctance. Participants in the second group listed the following barriers: forgot password and or username and not easy to use. Common barriers to patient portal adoption and use are difficulties accessing the portal due to username and password issues, and the complications of navigating the portal (Powell \& Myers, 2018).

Table 4. How patients learned about the portal $(\mathrm{N}=768)$

\begin{tabular}{|l|c|c|}
\hline \multicolumn{3}{|c|}{ How Patient learned about the Portal } \\
\hline Physician/Nurse & No. & $\%$ \\
\hline Email & 154 & $20.0 \%$ \\
\hline Front Desk & 63 & $8.2 \%$ \\
\hline Other: Facility/Friend & 301 & $39.2 \%$ \\
\hline Pamphlet & 21 & $2.7 \%$ \\
\hline Paperwork & 44 & $5.7 \%$ \\
\hline Practicum Student & 48 & $6.2 \%$ \\
\hline Total & 137 & $18.0 \%$ \\
\hline
\end{tabular}

Of all the patient portal users in the study, most self-declared that they were satisfied, and some non-users were willing to consider the utilization of the portal after participating in the study. Aljabril et al. (2018) found that there was no strong evidence between the satisfaction of patient portal use and actual utilization (Goldweig et al., 2013; Kruse et al., 2015; Neuner et al. 2015; Woollen et al., 2016).

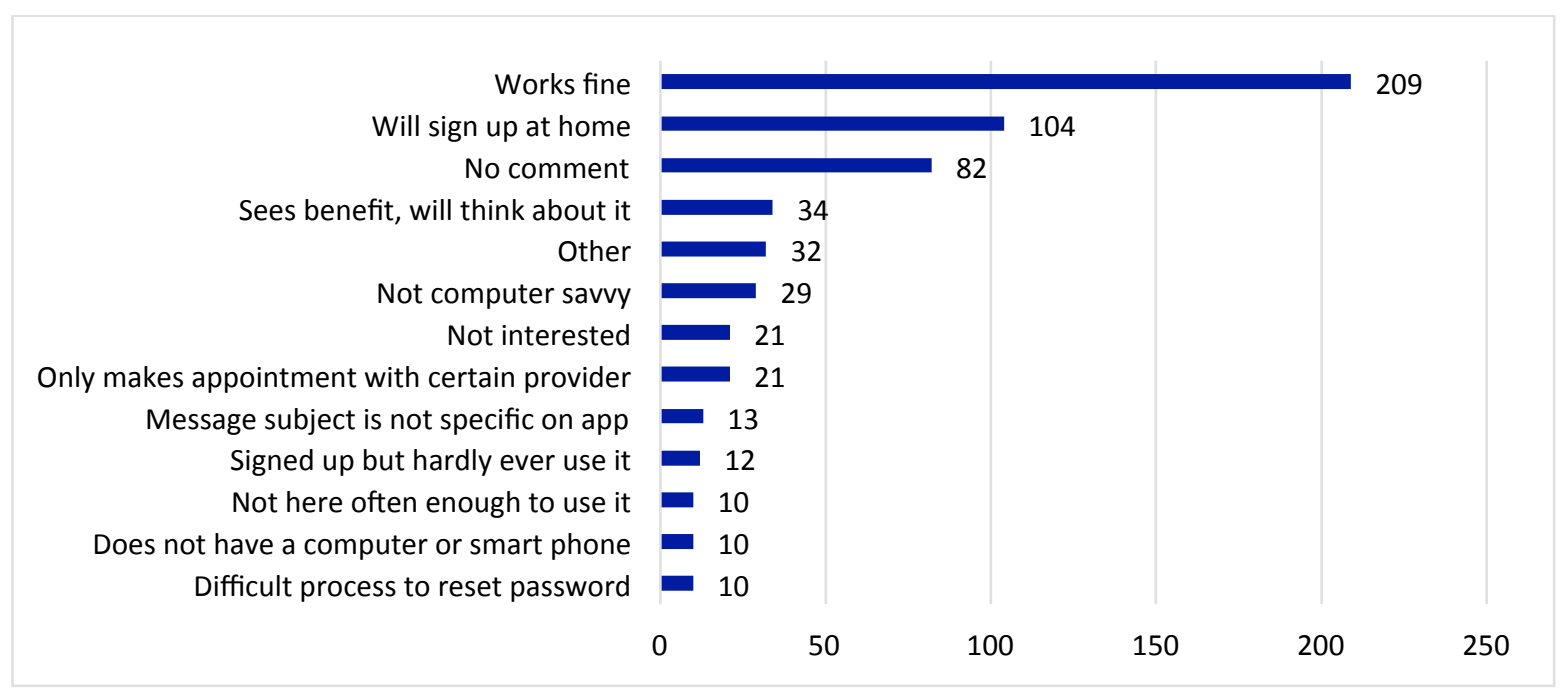

Figure 1. Participant Comments Collected $(\mathrm{N}=587)$ 
Figure 1 is a frequency breakout of participant comments. Not all participants gave a comment and some gave multiple comments. Comments were grouped together that were analogous by the research staff. For example, the patient comment "not computer savvy" was a compilation of, my son will sign me up because he is computer literate, someone with a computer who understands will sign me up, I do not understand computers, and I am not computer savvy at all. The grouped comments allowed the researches to understand the participant feelings and thoughts regarding the patient portal. Several responses of interest in Figure 1 include the following. Of the overall comments by respondents, 36\% (209 of 587) said the portal works fine and they were satisfied, while 18\% (104 of 587) stated they will sign up at home, and 14\% (82 of 587) of the participants had no comment.

\section{Discussion}

There are numerous methods to capture patient portal engagement and use rates. Patient portal log-ins capture report usage, although this method is void of functionality and context (Irizarry et al., 2015). Another method is to look at active (interaction with the portal) and passive (just logging in) (Perry et al., 2014). This exploratory study captured data that was self-reported. This initial data will eventually be foundational to a more comprehensive study of patient portal adoption and use at the hospital. The following is a discussion of information gathered from the semi-structured interview, observations, and comments.

\section{Usability and Functionality}

A basic understanding of usability refers to the interface of the system and its ease of navigation, interactivity, learnability, and content relevance (Lee \& Kozar, 2018). User friendliness including navigation of patient portals, which continues to be an issue with both patients and providers (Kruse et al., 2015). Although usability and functionality have some similarities yet differ, we discuss both as a single topic area as this was not the focus of the research. The clinical staff as well as participants, demonstrated frustration with the portal's usability and functionality. Comments stating frustration with usability and functionality included it was a difficult process to log in setting up a password, and username. Streamlining the log in process would go a long way to strengthen patient adoption and use of the portal. Other comments regarding the portal as being too busy. Partitioning the portal will increase ease of use. Consumer-focused technologies can be improved by making them patient-centered ensuring they foster robust communications enabling knowledge flow to patients and providers (Ancker et al., 2015). Patients that are actively using a portal regarding their health have better health related outcomes (Green \& Hibbard, 2011; Hibbard et al., 2010; Remmers, Hibbard, \& Mosen, 2009).

\section{Clinical}

More detail on the patient notes in the electronic medical record could be available. Messaging was available but there were problems. If a patient sent a message, then the physician responded to the message. However, if the patient wanted again to reply to the same message with the physician's response, then the patient could not reply to the message. The patient needed to create an entire new message and re-state the whole conversation with the new information from the physician. The patient had limited ability to make appointments with their general physician. 
At the time of the study, patients could not make appointments with specialists. Keeping data up to date in sync with the electronic medical record was also an area of concern. Accessible up-todate data is crucial for a complete and accurate medical history (Miller et al., 2016). The staff has stated that the electronic medical record does not indicate to them that the patient is a user of the portal. On many occasions when the patient is at the end of their appointment, the system prints out an authorization code for the portal, and that is how staff discover that the patient is not a user of the portal. Staff have stated that they need to be deep into the system before it becomes evident to them that a patient is not a portal user. Disruption of workflow infringing on time constraints are challenges limiting healthcare providers use of portals, thereby potentially decreasing accurate up-to-date information potentially minimizing or negatively affecting patient health outcomes (Miller et al., 2016).

\section{Administrative}

Many participants were not aware of the portal and its benefits. Ratliff-Schaub and Valleru (2017) suggested increasing awareness of patient portals including training clinical staff on registering patients is necessary to engage patients in portal use, which increases patient and provider communication creating better health outcomes. The hospital currently has pamphlets in multiple languages, which include included English, Spanish, and Haitian Creole (French based). Signage and pamphlets are a good strategy when generously available throughout the clinic settings, and will educate and increase awareness of the portal. This information can also be available on hospital websites and downloadable. Television monitors can also broadcast this information throughout the hospital where appropriate.

\section{Conclusion}

\section{Limitations}

There are limitations in this exploratory research study. Patient portal utilization is a quality metric for Meaningful Use. Several different methodologies used to measure patient portal adoption and use include patient logins and active interaction. This explorative study focused on adoption and use of the patient portal. It does not address all aspects of patient portal usage such as educational level, health literacy, income level, marital status and other demographic variables. A more inclusive study would include more demographic information, health literacy, and perhaps a look at how users come to the awareness and resistance to such technology using a survey-based instrument. We collected no PHI, nor did we have access to any electronic medical records. Participants of the study self-reported the data and information. We choose large departments within the hospital because we felt that we would get a good response. Ideally, some small departments could participate in giving a more inclusive sampling of the hospital. The focused semi-structured interview was not a validated instrument. We are anticipating that the findings will garner enough interest at the hospital allowing further exploration of the patient portal adoption and use rates for a more sophisticated study and analysis.

This exploratory research study conducted a one-on-one focused semi-structured interview collecting self-reported patient portal adoption and use data from 768 voluntary participants. Findings of interest included younger participants in the age group of 20 to 30 utilized the patient 
portal significantly less than all other age groups, and that there was no real difference between patient portal use based on gender. About 57.9\% (445 of 768) of all study participants were using the hospital's patient portal. The majority 57.5\% (256 of 445) of those who using the portal are between the ages of 41 to 60 (41 to 50 and 51 to 60 age groupings). This is $10.9 \%$ above what the hospital reported, though this is a sample. Most users were between the ages of 41 to 60 . Participants from location three had the highest utilization rates for the portal $32.1 \%$ (143 of 445). As we get older, we tend to take on health issues and often multiple health issues or comorbidities (two or more chronic diseases). These findings suggest that those in the age category of 41 to 60 may be facing more serious medical issues or dealing with multiple health issues and are more inclined to use their patient portal (Aljabril et. al. 2018; Hoogenbosch et. al., 2018; Oest et. al., 2018).

\section{Future Research}

The next step is to conduct a more comprehensive investigation of patient portal adoption awareness and resistance to use at the hospital. The issues identified from this semi-structured interview (functionality, education, \& awareness) require closer examination. Comments by participants on the comfort level with the patient portal demonstrates there is a need to measure health literacy and eHealth literacy. Measuring patient awareness, knowledge, and skills on how to use information technology and health literacy can help to determine patient comfort levels with eHealth (Norman \& Skinner, 2006). Utilizing a health literacy scale will identify health literacy needs, measuring them and developing a method to address those needs, and measuring the result of the intervention (Ownby, 2015). Addressing health literacy along with a more comprehensive analysis of demographic information, underserved ethnic and racial populations, and health issues will provide a more meaningful understanding of patient portal adoption and use (Coughlin, Srewart, Young, Heboyan, \& De Leo, 2018). There are opportunities to increase patient portal use through awareness education of both provider and patient and addressing health literacy (Coughlin et al., 2018; Tieu et. al., 2017).

\section{Acknowledgement}

To the anonymous reviewers, we wish to thank you for your critical assessment and feedback for this manuscript. Your comments were helpful, appreciated and incorporated. To the editors, editorial board, program committee chairs, co-chairs, organizers, coordinators, the committee members of the Online Journal of Applied Knowledge Management and the International Knowledge Management (KM) Conference, 2019 - were earlier draft of this manuscript was submitted - Thank You for their generous time and effort. Additional acknowledgements include Dr. Patrick Hardigan for his statistical insight. Dr. Arif M. Rana for his feedback on the project. Mr. John Santangelo, the hospital site preceptor, and informatics student, Ms. Jemimah Arolsafe, for being instrumental in all aspects of this study.

\section{References}

Aljabril, D., Dumitrascu, A., Burton, M. C., White, L., Kahn, M., Xirasagar, S., Horner, R., \& Naessens, J. (2018). Patient portal adoption and use by hospitalized cancer patients: A 
retrospective study of its impact on adverse events, utilization, and patient satisfaction. BMC Medical Informatics and Decision Making, 18(1), 1-12. https://www.doi.org/10.1186/s12911-018-0644-4

Ancker, J. S., Osorio, S. N., Cheriff, A., Cole, C. L., Silver, M., \& Kaushal, R. (2015). Patient activation and use of an electronic patient portal. Informatics for Health and Social Care, 40, 254-266.

Baldwin, J. L., Singh, H., Sittig, D. F., \& Giardina, T. D. (2017). Patient portals and health apps: Pitfalls, promises, and what one might learn from the other symptoms. Healthcare, 3, 8185.

Cain, K., \& Hanania, R. (2013). Patients want granular privacy control over health information in electronic medical records. Journal of the American Medical Informatics Association, 20(7), 7-15.

Cepeda-Carrion, I., Martelo-Landroguez, S., Leal-Rodriguez, A. L., \& Leal-Millan, A. (2016). Critical processes of knowledge management: An approach toward the creation of customer value. European Research on Management and Business Economics, 23, 1-7.

Centers for Medicare and Medicaid Services (2013). Details for title: 2013-07-24. CMS.gov. Retrieved from: https://www.cms.gov/Outreach-and-Education/Outreach/NPC/NationalProvider-Calls-and-Events-Items/2013-07-24-EHR-Incentive.html

Choi, B., \& Lee, H. (2002). Knowledge management strategy and its link to knowledge creation process. Expert Systems with Applications, 23, 173-187.

Committee on Quality Health Care in America, Institute of Medicine (2001). Crossing the quality chasm: A new health system for the 21st century. Washington, D.C.: National Academy Press.

Coughlin, S. S., Srewart, J. L., Young, L., Heboyan, V., \& De Leo, G. (2018). Health literacy and patient web portals. International Journal of Medical Informatics, 113, 43-48.

Crosswaite, C., \& Curtice, L. (1994). Disseminating research results - the challenge of bridging the gap between research and health action. Health Promotion International, 9, 289-296.

Dhillon, K., Tan, E., Akseer, R., Alhosani, M. S., Ho, G. F., Lim, S. H. E., \& Jamaluden, A. N. S. J. (2018). EMR access and confidentiality based on patient and hospital staff perspectives. The Open Public Health Journal, 11, 533-545. http://www.doi.org/10.2174/1874944501811010533

Epic (2019). About us. Epic. Retrieved from: http://www.epic.com/about

Furukawa, M. F., King, J., Patel, V., Hsiao, C. J., Adler-Milstein, J., \& Jha, A. K. (2014). Despite substantial progress in HER adoption, health information exchange and patient engagement remain low in office settings. Health Affairs, 33, 1672-1679.

Goldweig, C. L., Orshansky, G., Paige, N. M., Towfigh, A. A., Haggstrom, D. A., \& Miake-lie, L. (2013). Electronic patient portals: Evidence on health outcomes, satisfaction, efficiency, and attitudes: a systematic review. Annals of Internal Medicine, 159, 677-687. 
Gowen, C. R., Henagan, S. C., \& McFadden, K. L. (2009). Knowledge management as a mediator for the efficiency of transformational leadership and quality management initiatives in U.S. healthcare. Healthcare Management Review, 34(2), 129-140.

Green J., \& Hibbard, J. H. (2011). Why does patient activation matter? An examination of the relationship between patient activation and health related outcomes. Journal of General Internal Medicine, 27, 520-526.

Hibbard, J. M., \& Mahoney, E. (2010). Toward a theory of patient and consumer activation. Patient Education Counsel, 78, 377-381.

Haun, J. N., Patel, N. R., Lind, J. D., \& Antinori, N. (2015). Large-scale survey findings inform patients' experiences in using secure messaging to engage in patient-provider communication and self-care management: A quantitative assessment. Journal of Medical Internet Research, 17(12), 1-12. http://www.doi.org/10.2196/jmir.5152

Hoogenbosch, B., Postma, J., Ginkel, J. M., Tiemessen, N., Delden, J. J., \& Os-Medendorp, H. (2018). Use and uses of a patient portal: Cross sectional study. Journal of Medical Internet Research, 20(9), 1-12. http://www.doi.org/10.2196/jmir.9418

Irizarry, T., DeVito, I. T., \& Curran, C. R. (2015). Patient portals and patient engagement: A state of science review. Journal of Medical internet Research, 17(6), 1-15. http://www.doi:10.2196/jmir.4255

Kruse, C. S., Argueta, D. A., Lopez, L., \& Nair, A. (2015). Patient and provider attitudes towards the use of patient portals for the management of chronic disease: A systematic review. Journal of Medical Internet Research, 17(2), 1-10. http://www.doi.org/10.2196/jmir.3703

Krause, C. S., Bolton, K., \& Frekrikis, G. (2015). The effect of patient portals on quality outcomes and its implications to meaningful use: A systematic review. Journal of MedicalInternet Research, 17(2), 1-8. http://www.doi.org/10.2196/jmir.3171

Lee, Y., \& Kozar, K. A. (2018). Understanding a Web site usability: Specifying and measuring constructs and their relationships. Decision Support Systems, 52(2), 450-463.

Mayberry, L. S., Kripalani, S., Rothman, R. L., \& Osborn, C. Y. (2011). Bridging the digital divide in diabetes: Family support and implications for health literacy. Diabetes Technology Therapeutics, 13(10), 1005-1012. http://www.doi.org/10.1089/dia.2011. 0055

Miller, D. P., Latulipe, C., Melius, K. A., Qunadt, S. A., \& Arcury, T. A. (2016). Primary care providers' view of patient portals: Interview study of perceived benefits and consequences. Journal of Medical Internet Research, 18(1), 1-11. http://www.doi.org/10.2196/jmir.4953

National Coordinator for Health Information Technology (2019). Patient portal benefits patient care and provider workflow. Retrieved from: https://www.healthit.gov/case-study/ patient-portal-benefits-patient-care-and-provider-workflow 
National Coordinator for Health Information Technology (2019). What is a patient portal? Retrieved from: https:/www.healthit.gov/faq/what-patient-portal

National Coordinator for Health Information Technology (2018). Data Brief No. 40, 1-17. Retrieved from: http://www.healthit.gov/

Neuner, J., Fedders, M., Caravella, M., Bradford, M., \& Schapira, L. (2015). Meaningful use and the patient portal: Patient enrollment, use, and satisfaction with patient portals at a lateradoption center. American Journal of Medical Quality, 30, 105-113.

Norman, C. D., \& Skinner, H. A. (2006). eHEALS: The eHealth literacy scale. Journal of Medical Internet Research, 8(4), 1-10. http://www.doi.org/ 10.2196/jmir.8.4.e27

Oest, S. E., Hightower, M., \& Krasowski, M. D. (2018). Activation and utilization of an electronic health record patient portal at an academic medical center - impact of patient demographics and geographic location. Academic Pathology, 5, 1-9.

Osborn, C. T., Mayberry, L. S., Wallstonka, K. A., Johnson, K. B., \& Elast, T. A. (2013). Understanding patient portal use: Implications for medication management. Journal of Medical Internet Research, 15(7), 1-12. http://www.doi.org/10.2196/jmir.2589

Osborn, C. Y., Maryberry, L. S., Mulvaney, S. A., \& Hess, R. (2010). Patient web portals to improve diabetes outcomes: A symmetrical review. Current Diabetes Reports, 10(6), 422-435. http://www.doi.org/10.1007/s11892-010-0151-1

Ownby, R. (2015). Flight/vitas user manual. Fort Lauderdale, FL: Enalan Communications, Inc.

Pavani, R. (2008). Knowledge sharing networks related to hospital quality measurement and reporting. Healthcare Management Review, 33(3), 253-263.

Perry, M. P., Robben, S. H., Schers, H., Heinen, M., Olde Rikkert, M. G., \& Melis, R. (2014). Which frail older patients use online health communities and why? A mixed methods process evaluation of use of health and welfare portal. Journal of Medical Internet Research, 16(12), 1-14. http://www.doi.org/10.2196/jmir.3609

Powell, K. R., \& Myers, C. R. (2018). Electronic patient portals: Patient and provider perceptions. Online Journal of Nursing Informatics, 22(1).

Ratliff-Schaub, K., \& Valleru, J. (2017). Increasing patient portal activation in a pediatric subspecialty clinic. Pediatric Quality and Safety, 6(2), 1-6.

Razzaque, A. \& Karolak, M. (2010). Knowledge management and electronic health record facilitate clinical support to improve healthcare quality. Proceedings of the International Conference on E-Business, Management and Economics, 3, 238-242, Hong Kong: IACSIT Press.

Remmers, C., Hibbard, J., \& Mosen, D. M. (2009). Is patient activation associated with future health outcomes and healthcare utilization among patients with diabetes? Journal of Ambulatory Care Management, 32, 320-327.

Rittenhouse, D. R., Ramsay, P. P., Casalino, L. P., McClellan, S., Kandel, Z. K., \& Shortell, S. M. (2017). Increased health information technology adoption and use among small 
primary care physician practices over time: A national cohort study. Annals of Family Medicine, 15, 56-62.

Sarkar, U., Karter, A. J., Liu, J. Y., Adler, N. E., Nguyen, Rr., \& Lopez, A., \& (2011). Social disparities in Internet patient portal use in diabetes: evidence that the digital divide exist beyond access. Journal of the American Medical Informatics Association, 18(3), 318321.

Schwartz, P., Caine, K., Alpert, S., Meslin, E., Carroll, A., \& Tierney, W. (2015). Patient preferences in controlling access to their electronic health records: A prospective cohort study in primary care. Journal of General Internet Medicine, 30(S1), 25-30. http://www.doi.org/10.1007/s11606-014-3054-z

Sun, R., Korytkowski, M. T., Sereika, S. M., Saul, M. I., Li, D., \& Burke, L. E. (2018). Patient portal use in diabetes management: Literature review. Journal of Medical Internet Research, 3(4), 1-14. http://www.doi.org/10.2196/11199

Tenforde, M., Nowacki, A., Jain, A., \& Hickner, J. (2012). The association between personal health record use and diabetes quality measures. Journal of General Internal Medicine, 27(4), 420-424. http://www.doi.org/10.1007/s11606-011-1889-0

Tenforde, M., \& Hickner, J. (2011). The value of personal health records for chronic disease management: what do we know? Family Medicine, 43(5), 351-354.

United States Department of Health and Human Services (2018). Health information privacy. Retrieved from: https://www.hhs.gov/hipaa/for-professionals/privacy/laws-regulations/

Tieu, L., Schillinger, D., Sarkar, U., Hoskate, M., Hahn, K. J., Ratanawongsa, N. Rlaston, J. D., \& Lyles, C. R. (2078). Online patient websites for electronic health record access among vulnerable populations: Portals to nowhere? Journal of the American Medical Informatics Association, 24(e1), e47-e57. http://www.doi.org/10.1093/jamia/ocw098

Woollen, J., Perry, J., Wilcox, L., Sackeim, A., Restaino, S., Raza, S. T., ... Bakken, S. (2016). Patient experiences using an inpatient personal health record. Applied Clinical Informatics, 7(2), 446-460.

World Health Organization (2018). eHealth at WHO. Retrieved from: http://www.who.int/ehealth/en/

Zickmund, S. L., Hess, R., Bryce, C. L., McTigue, K. M., Olshansky, E., Fitzgerald, K., \& Fisher, G. S., (2008). Interest in the use of computerized patient portals: Role of the provider-patient relationship. Journal of General Internet Medicine, 23(S1), 20-26. http://www.doi.org/10.1007/s1 1606-007-0273-6 


\section{Authors Biographies}

Stephen E. Bronsburg, Ph.D., M.H.S.A. is an Associate Professor, Academic Advisor and Practicum Course Director at Nova Southeastern University (NSU) Dr. Kiran C. Patel College of Osteopathic Medicine (KPCOM), Department of Health Informatics, Biomedical Informatics Program, Fort Lauderdale, Florida, USA. He is a board member for the South Florida Healthcare Information and Management Systems Society (SFHIMSS). He has conducted and collaborated on numerous health information technology (HIT) research projects with health

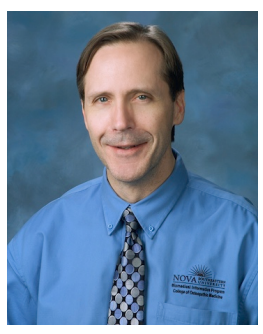
professionals and graduate students. Selected past research includes developing Avatars to teach addiction counseling skills to healthcare providers, developed and implemented a phone application to address addiction, and incorporating mHealth technology interventions addressing chronic disease and addiction. National and international scholarly activities include peerreviewed presentations, conference proceedings, journal publications; international journal review board as well as HIT focused textbook reviews.

Marcia Durity, M.S. is a Senior Library Assistant (Supervisor) at the Alvin Sherman Library on NSUs main campus. She graduated with her Master of Science degree in Biomedical Informatics from NSU KPCOM in December 2017. She previously volunteered and conducted research on evaluating the effects of resveratrol and genistein on VEGF expression in LNCaP prostate cancer cells at the Rumbaugh-Goodwin Institute for Cancer Research, Inc. (RGI) under Dr. Appu Rathinavelu at NSU in 2009-2011. She presented her findings with a poster presentation at the Annual Biomedical Research

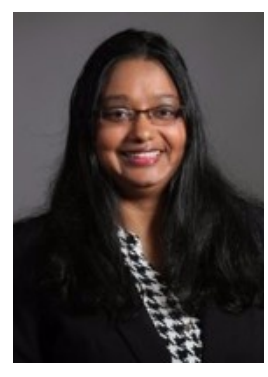
Conference for Minority Students (ABRCMS) conference in St. Louis, Missouri in 2011. In addition, Marcia is furthering her knowledge by learning SQL and Lean Six Sigma techniques for process improvement and efficiency.

Michelle M. Ramim, Ph.D. is an adjunct professor at NSU KPCOM, Department of Health Informatics, Biomedical Informatics Program, and College of Computing and Engineering (CCE), Department of Information Systems and Cybersecurity, Fort Lauderdale, Florida, USA. She has extensive experience as an information technology (IT) consultant for small and mid-size organizations. She has directed the development and implementations of several IT projects in the healthcare field and held a license as well as practiced

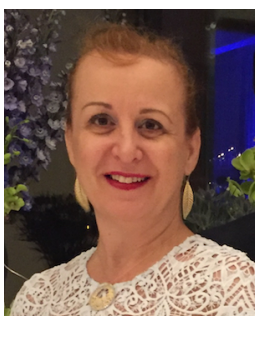
in the 1990s as an Assistant Living Facility Administrator. Her current research interests include healthcare IT, cybersecurity and crisis management, ethical and legal aspects of computing, as well as ethical decision-making. She has published articles in peer-reviewed outlets including journals, conference proceedings, encyclopedias, and an invited chapter. Moreover, she has been serving as a referee research reviewer for national and international scientific journals, conference proceedings, as well as MIS textbooks. She earned her bachelor's degree from Barry University in Miami Florida. Dr. Ramim received her MBA from Florida International University. She completed her Ph.D. in Information Systems at the formerly known Graduate School of Computer and Information Sciences, Nova Southeastern University in the area of ethical decision making in computing. 